\title{
Ambulatory management of large primary spontaneous pneumothorax
}

\author{
To the Editor:
}

In a recent issue of the European Respiratory Journal, MASSONGO et al. [1] reported the results of a prospective study dealing with ambulatory management of primary spontaneous pneumothorax (PSP) using a pigtail catheter with one-way valve in a series of 60 consecutive patients. The authors reported a success rate of $83 \%$, a 1 -year recurrence rate of $17 \%$ and full outpatient management in $50 \%$ of the patients. However, they included in their analysis $12(20 \%)$ patients with small PSP and no breathlessness, which were treated conservatively, and all of these patients demonstrated complete re-expansion by day 7 . As the definition of success was based on the complete or nearly complete re-expansion of the lung on chest radiography at 7 days, these 12 patients alter the results, as the size of the pneumothorax determines the rate of resolution [2]. Therefore, in large PSP, the success rate is actually $79 \%$ (38 out of 48 ) and $37 \%$ (18 out of 48) had full outpatient management. However, we strongly agree with the usefulness of such management of spontaneous pneumothoraces. We would like to highlight the importance of the four "discharge safety criteria" described by the authors: 1) patient in stable condition; 2) time to reach the hospital from patient's home $<1 \mathrm{~h}$ by any means of transport; 3) patient not living alone; and 4) patient able to understand and implement instructions given in the case of problems. We think that with this technique, patient could be discharge even at night. Therefore, the fifth criterion (time of discharge earlier than 20:00 h) seems not so relevant. To conclude, we would like to thank MAssongo et al. [1] for this work, which shows that ambulatory management of large PSP is safe, efficient and cost-effective. This technique is not mentioned in current guidelines [2-4] and should be included in future recommendations. As recently stated by BRIMS and MASKELL [5], prospective studies are lacking in this field and we need randomised clinical trials to clearly demonstrate the benefit of this ambulatory management, such as that described by the authors of the present paper.

0

@ERSpublications

Ambulatory management of large primary spontaneous pneumothorax with small-bore catheter: yes we can! http://ow.ly/qmVzv

Stéphane Jouneau ${ }^{1,2}$, Laurent Sohier ${ }^{3}$ and Benoit Desrues ${ }^{1}$

${ }^{1}$ Dept of Respiratory Medicine, Pontchaillou Hospital, Rennes 1 University, Rennes, ${ }^{2}$ IRSET UMR1085, Rennes 1 University, Rennes, and ${ }^{3}$ Dept of Respiratory Medicine, Centre Hospitalier Bretagne Sud, Lorient, France.

Correspondence: S. Jouneau, Dept of Respiratory Medicine, Pontchaillou Hospital, Rennes 1 University, 2 rue Henri Le Guilloux, 35033 Rennes Cedex 9, France. E-mail: Stephane.jouneau@chu-rennes.fr

Received: June 292013 | Accepted: July 042013

Conflict of interest: Disclosures can be found alongside the online version of this article at www.erj.ersjournals.com

\section{References}

1 Massongo M, Leroy S, Scherpereel A, et al. Outpatient management of primary spontaneous pneumothorax: a prospective study. Eur Respir J 2014; 43: 582-590.

2 MacDuff A, Arnold A, Harvey J. Management of spontaneous pneumothorax: British Thoracic Society Pleural Disease Guideline 2010. Thorax 2010; 65: Suppl. 2, ii18-ii31.

3 Baumann MH, Strange C, Heffner JE, et al. Management of spontaneous pneumothorax: an American College of Chest Physicians Delphi consensus statement. Chest 2001; 119: 590-602.

4 De Leyn P, Lismonde M, Ninane V, et al. Guidelines Belgian Society of Pneumology. Guidelines on the management of spontaneous pneumothorax. Acta Chir Belg 2005; 105: 265-267.

5 Brims FJ, Maskell NA. Ambulatory treatment in the management of pneumothorax: a systematic review of the literature. Thorax 2013; 68: 664-669. 